\title{
Making every new hire count
}

The Cataloging Services Department at the University of Virginia Library has experimented with an approach to hiring that seeks to bring each new employee into the best possible learning environment. We wanted to make the socialization and training more effective by empowering existing staff to take responsibility for the success of new employees.

The program involves working with existing staff before the employee arrives. The main components are (1) including staff in the hiring and orientation process and (2) assisting staff in analyzing how they influence new employees and what they can do to ensure their success.

Staff are included on search committees for new hires or meet with candidates during interviews. Staff are also involved in preparing orientation/training programs. We use a broad base of trainers and have found many benefits, one being the shared responsibility the trainers take.

We schedule a meeting before the employee arrives to go over last minute details of the orientation. At those meetings we have presented the ideas of Fairfield-Sonn ("Work Group Reactions to New Members: Tool or Trap in Making Selection Decisions?," Public Personnel Management, Winter 1984), who

physical condition or whose uncertain future access necessitates urgent attention. Grants of up to $\$ 20,000$ are available to cover travel $(\$ 2,800)$ living expenses (not to exceed $\$ 1,250$ / month) and research expenses. Although the first application deadline was May 11, 1993 , proposals will be reviewed at bi-monthly deadlines, subject to availability of funds. Contact NEH at (202) 606-8210 or e-mail: nehres@gwuvm.gwu.edu with "archival research" in the subject line.

\section{Springer journal preview service}

Springer-Verlag is offering the table of contents and article abstracts of 30 scientific journals via Internet three to six weeks before publication of the printed journal. Access to the table of contents is free; access to the abstracts is available for a $\$ 20$ annual fee payable only by credit card. This offer is not available to commercial information suppliers. The aim of this two-year developed a model for predicting the initial reactions of a group to a new member.

He examined two dimensions: group receptivity (how open or closed a group is to the new member) and position placement (how much power the new member exerts on the groupe.g., boss or peer). Based on these two dimensions Fairfield-Sonn predicted four reactions: nurturance (open group/boss position), acceptance (open group/peer position), confrontation (closed group, boss position) and avoidance (closed group/peer position).

We ask the group to develop strategies which will lead to an open group response, thereby encouraging the "nurturance" and "acceptance" reactions. Discussion of these strategies has a tendency to reinforce positive behaviors and allow a sense of collective responsibility to develop.

With this approach new staff members have been acclimated to the work and social environment in a manner that encourages success. We tailor the program to the group, but always include these elements: involve staff in the selection process, assign as many staff as possible for training and orientation, and work with existing staff to develop their sense of collective responsibility.-Susanne Glass, University of Virginia

project is to promote rapid scientific exchange electronically. The address of the mailserver is svjps@dhdspri6 (inbinet/earn). Send an e-mail message consisting of the word "help" to obtain detailed information about the service and how to take advantage of the offer.

\section{Compile a subject list of Internet resources}

CERL News would like to print brief subject lists of Internet resources such as the one prepared by Jeanne Brown on architecture studies that appeared on page 189 of the April 1993 issue. If you are interested in preparing a brief list in your area of expertise contact: Mary Ellen Davis, Editor \& Publisher, CERL News, $50 \mathrm{E}$. Huron St., Chicago, IL 60611 or e-mail: U38398@uicvm.uic.edu. 